11

\title{
Поглотители СВЧ излучения на основе гофрированных композитов с углеродными волокнами
}

\author{
(С) Д.С. Быченок, ${ }^{1}$ А.О. Плющ, ${ }^{1}$ Г.В. Горохов, ${ }^{1}$ В.С. Быченок, ${ }^{2}$ П.П. Кужир, ${ }^{1,3,4}$ С.А. Максименко ${ }^{1,3,4}$ \\ ${ }^{1}$ Институт ядерных проблем Белорусского государственного университета, \\ 220030 Минск, Белоруссия \\ ${ }^{2}$ Конструкторское бюро „Мир“, Белорусская государственная академия авиации, \\ 220096 Минск, Белоруссия \\ ${ }^{3}$ Рязанский государственный радиотехнический университет, \\ 390005 Рязань, Россия \\ ${ }^{4}$ Томский государственный университет, \\ 634050 Томск, Россия \\ e-mail: dzmitrybychanok@ya.ru
}

(Поступило в Редакцию 12 января 2016 г. В окончательной редакции 21 мая 2016 г.)

\begin{abstract}
Проведен комплексный анализ зависимости коэффициента поглощения полимерных композитов с немагнитными углеродными включениями от вещественной и мнимой частей комплексной диэлектрической проницаемости, а также от толщины материала в диапазоне частот 26-37 GHz. Получены композиты, содержащие $0.2 \mathrm{wt}$ \% углеродных волокон. Экспериментально установлено, что гофрирование поверхности композита приводит к существенному увеличению коэффициента поглощения (с 63 до 92\% на частоте $30 \mathrm{GHz}$ при толщине $4.50 \mathrm{~mm}$ ) при уменьшении массы образца (на 28\%). Предложена методика расчета коэффициента поглощения гофрированных композитов в СВЧ диапазоне.
\end{abstract}

Исследованиям электромагнитных свойств композиционных материалов на основе различных форм углерода посвящено большое количество работ [1-7]. Установленные в $[1,6]$ особенности взаимодействия электромагнитного излучения с наноуглеродными композитами показывают перспективность использования данных материалов для широкого круга научно-практических применений. Особенно привлекательны композиты с углеродными и наноуглеродными включениями в качестве поглотителей электромагнитного излучения при разработке технологии снижения заметности для радара. Для решения ряда практических задач, например при расчетах компонентов фюзеляжа летательных аппаратов, важно знать, как параметры конструкционного материала влияют на его поглощательные свойства в СВЧ диапазоне.

Поглощение СВЧ излучения может осуществляться за счет омических потерь [8-10], ферромагнитного резонанса в магнитных материалах [11], дипольной релаксации [12], а также за счет структуры в метаматериалах [13]. В настоящей работе мы остановимся на исследовании поглощательных свойств немагнитных композиционных материалов с электропроводящими углеродными включениями в диапазоне частот $26-37 \mathrm{GHz}$ $\left(K_{a}\right.$-зона). Данный частотный диапазон используется для связи со спутниками, в бортовой электронике, а также для определения скорости движущихся объектов. Как известно, малые концентрации углеродных включений в композитах позволяют изменять значения комплексной диэлектрической проницаемости $\varepsilon$ полимерной матрицы и получать материалы с контролируемым поглощением. Увеличить коэффициент поглощения в композитах можно за счет использования антиотражающих свойств гоф- рированных поверхностей. Данный прием заимствован из природы и напрямую связан с эффектом глаза ночной бабочки (moth-eye effect) [14-16]. Ниже мы подробно рассмотрим поглощательные свойства гофрированных поверхностей в СВЧ. Для начала проанализируем особенности взаимодействия электромагнитного излучения, нормально падающего на плоскопараллельный композит (рис. 1, $a$ ), помещенный в прямоугольный волновод, а затем рассмотрим свойства гофрированных композитов (рис. $1, b)$.

Для описания электромагнитных свойств воспользуемся длинноволновым приближением, подробно описанным в [8]. Для расчета коэффициентов отражения $R$ и
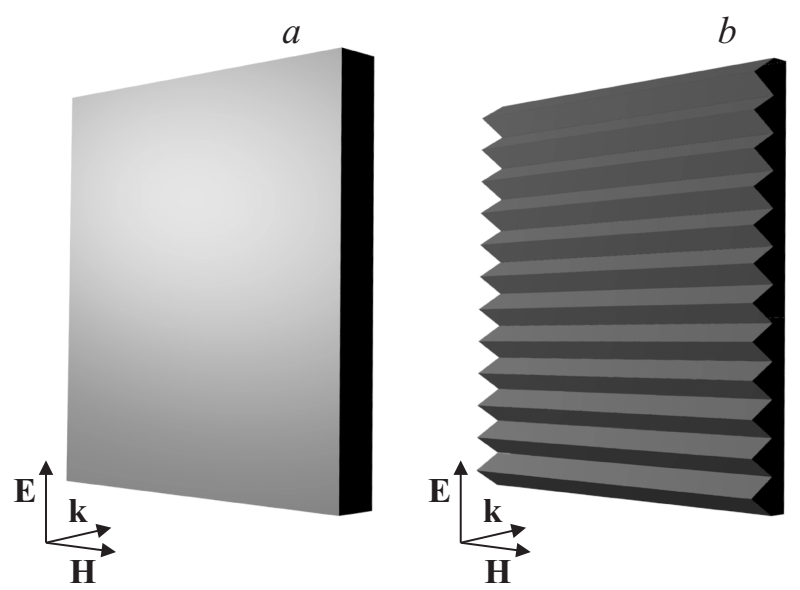

Рис. 1. Взаимная ориентация $(a)$ плоскопараллельного и $(b)$ гофрированного композитов относительно падающей электромагнитной волны с волновым вектором $\mathbf{k}$ и напряженностью электрического и магнитного полей $\mathbf{E}$ и $\mathbf{H}$ соответственно. 
пропускания $T$ плоскопараллельного однородного слоя толщиной $\tau$ можно использовать формулы Френеля либо непосредственно уравнения Максвелла. Из них могут быть получены значения электрического и магнитного полей в на границах слоя. В матричной записи при нормальном падении электромагнитной волны на образец в волноводе эти поля принимают вид (здесь и далее уравнения записаны с использованием единиц СИ для плоских волн $\exp (i \omega t-i k z)) \quad[17,18]$ :

$$
\left[\begin{array}{l}
E_{1} \\
H_{1}
\end{array}\right]=\left[\begin{array}{c}
\cos \left(k_{t} \tau_{0}\right) i \sin \left(k_{t} \tau_{0}\right) k_{0} / k_{t} \\
i \sin \left(k_{t} \tau_{0}\right) k_{t} / k_{0} \cos \left(k_{t} \tau_{0}\right)
\end{array}\right]\left[\begin{array}{l}
E_{2} \\
H_{2}
\end{array}\right],
$$

где $E_{1}, H_{1}$ и $E_{2}, H_{2}$ - значения электрического и магнитного полей на левой и правой границах образца толщиной $\tau_{0}, k_{t}=\frac{2 \pi}{\lambda a} \sqrt{n^{2} a^{2}-\lambda^{2} / 4}$ и $k_{0}=\frac{2 \pi}{\lambda a} \sqrt{n_{0} a^{2}-\lambda^{2} / 4}-$ волновые числа внутри слоя с коэффициентом преломления $n$ и в воздухе (коэффициент преломления $n_{0}=1$ ) внутри волновода шириной $a=7.2 \mathrm{~mm}$ соответственно; $\lambda=c / v$, где $c=3 \cdot 10^{8} \mathrm{~m} / \mathrm{s}, v-$ частота. Первый множитель с правой стороны выражения (1) известен как характеристическая матрица слоя.

В случае многослойной системы (например, пленка на подложке) характеристическая матрица всей структуры может быть рассчитана как произведение матриц всех входящих в ее состав слоев. В этом случае коэффициенты $R, T N$-слойной структуры внутри волновода имеют вид

$$
\begin{gathered}
R=\left(n_{0}-C / B\right)^{2} /\left(n_{0}+C / B\right)^{2}, \\
T=4 n_{0} /\left(n_{0} B+C\right)^{2},
\end{gathered}
$$

где

$$
\left[\begin{array}{l}
B \\
C
\end{array}\right]=\left\{\prod_{t=1}^{N}\left[\begin{array}{c}
\cos \left(k_{t} \tau\right) i \sin \left(k_{t} \tau\right) k_{0} / k_{t} \\
i \sin \left(k_{t} \tau\right) k_{t} / k_{0} \cos \left(k_{t} \tau\right)
\end{array}\right]\right\}\left[\begin{array}{c}
1 \\
n_{0}
\end{array}\right] .
$$

Поскольку для немагнитных материалов $n=\sqrt{\varepsilon}$ $=\sqrt{\varepsilon^{\prime}-i \varepsilon^{\prime \prime}}$, использование предложенной выше модели позволяет рассчитывать электромагнитный отклик материалов с заданными значениями комплексной диэлектрической проницаемости $\varepsilon$. Зависимость коэффициента поглощения $A=1-R-T$ от компонент $\varepsilon$ композита толщиной $4.50 \mathrm{~mm}$ на частоте $30 \mathrm{GHz}$ представлена на рис. 2.

Анализ рис. 2 показывает, что для любого значения $\varepsilon^{\prime}$ всегда существует значение $\varepsilon^{\prime \prime}$, при котором коэффициент поглощения принимает максимальные для данной толщины значения. Аналогичный максимум поглощения наблюдался в работе [19], посвященной ультратонким графеновым пленкам. Из рис. 2 также видно, что для получения максимальных значений поглощения (84\% для композитов толщиной $4.50 \mathrm{~mm}$ на частоте $30 \mathrm{GHz}$ ) необходимо использовать материалы с минимальной $\varepsilon^{\prime}$. Именно поэтому при разработке промышленных поглотителей используются пористые материалы [20].

При увеличении толщины положение максимумов смещается вследствие интерференции, однако в целом

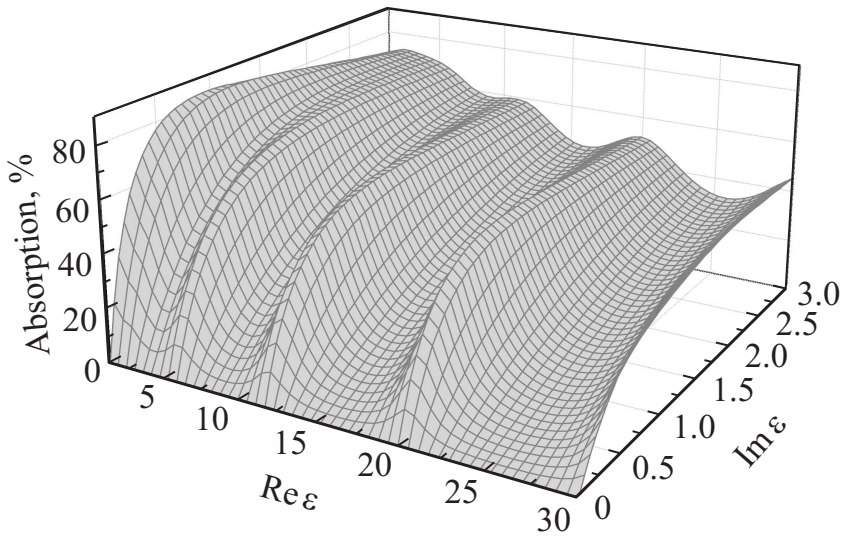

Рис. 2. Зависимость коэффициента поглощения от компонент диэлектрической проницаемости композита толщиной $4.50 \mathrm{~mm}$ на частоте $30 \mathrm{GHz}$.

поглощение возрастает, причем максимум становится более острым и смещается в область меньших значений $\varepsilon^{\prime \prime}$. При уменьшении толщины период осцилляций на рис. 2 увеличивается, а поглощение в целом уменьшается. Например, для композита толщиной $1 \mathrm{~mm}$ максимальный возможный коэффициент поглощения на частоте $30 \mathrm{GHz}$ составляет 53\%. Лимит поглощения на частоте $30 \mathrm{GHz}$ в ультратонких пленках при $\tau \rightarrow 0$ достигает 50\% [19].

Эффективность экранировки композитов на основе углеродных волокон (УВ) неоднократно обсуждалась в литературе [9,21]. Поэтому в качестве наполнителя для композитов был выбран углеродный флок (УФ) [22], приготовленный из углеродной нити УРАЛ-Н-100 [23]. Средний диаметр используемых углеродных волокон (УВ) составлял $5 \mu \mathrm{m}$, длина волокон $-1 \mathrm{~mm}$ (СЭМ-изображение представлено на рис $3, a$ ). Отметим несколько аргументов в пользу использования УВ для получения поглощающих покрытий. Из-за сильной экранировки, вызванной влиянием деполяризации, в композитах на основе наноуглеродных включений необходимо достигать порог перколяции для достижения существенного поглощения [1-7]. В свою очередь, при использовании углеродных волокон, обладающих правильной цилиндрической формой и высоким соотношением поперечных размеров (aspect ratio), влиянием деполяризации можно пренебречь. Проводимость УВ достаточно велика, но при этом толщина скин-слоя в $K_{a}$-зоне превышает диаметр волокон, поэтому они взаимодействуют с излучением всем своим объемом. Это позволяет создавать на основе УВ композиты с высоким коэффициентом поглощения при концентрации включений ниже порога перколяции.

Композиты на основе эпоксидной смолы марки ЭД-20, содержащие $0.2 \%$ (по массе), УФ приготавливались по методике, подробно описанной в [7]. $11.8 \mathrm{mg}$ УФ диспергировались в $10 \mathrm{ml}$ этанола в ультразвуковой ванне в течение $8 \mathrm{~min}$. Затем в полученную суспен- 


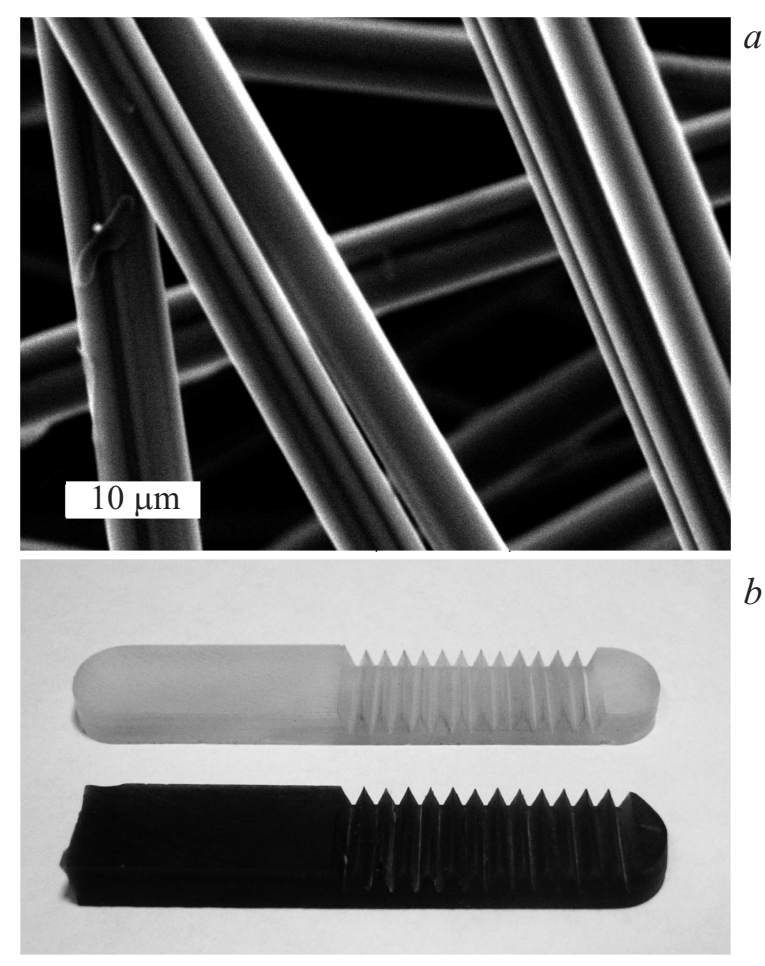

Рис. 3. $a-$ СЭМ-изображение углеродных волокон, входящих в состав углеродной нити УРАЛ-Н-100; $b-$ общий вид гофрированных композитов.

зию добавлялось $5 \mathrm{~g}$ эпоксидной смолы ЭД-20. Полученная смесь подвергалась обработке ультразвуком в течение $8 \mathrm{~min}$, после чего помещалась в печь при температуре $80^{\circ} \mathrm{C}$ на $3 \mathrm{~h}$ для удаления спирта. После испарения этанола смесь снова подвергалась обработке ультразвуком в течение $8 \mathrm{~min}$. Затем к смеси смолы и УФ добавлялось $0.55 \mathrm{~g}$ отвердителя ПЭПА. После ручного перемешивания в течение $5 \mathrm{~min}$ композит заливался в формочки. Затвердевание образцов происходило в течение $16 \mathrm{~h}$ при комнатной температуре, после чего композиты помещались на $3 \mathrm{~h}$ в печь при $80^{\circ} \mathrm{C}$ для окончательной полимеризации.

В отличие от наноуглеродных композитов даже кратковременная обработка УФ ультразвуком позволяла получать суспензии из отдельных волокон без образования агломератов. Это позволило существенно ускорить процесс приготовления композитов.

После окончательной полимеризации образцы композитов извлекались из формочек, шлифовались до толщины $h=4.50 \mathrm{~mm}$ и подвергались фрезерованию конической фрезой на станке с ЧПУ [24]. Угол раствора конической фрезы составлял $45^{\circ}$, глубина фрезерования $d h=2.5 \mathrm{~mm}$. Масса фрезерованной части композита уменьшалась на 28\%. Общий вид полученных композитов представлен на рис. $3 b$.

В длинноволновым приближении гофрированный композит может рассматриваться как плоскопараллельный слой с пространственной зависимостью коэффициента преломления $n$ [8]. Зависимость от координаты $x$ усредненного коэффициента преломления гофрированного композита может быть записана как

$$
\begin{gathered}
n(x)=n_{c}(1-S(x))+n_{0} S(x), \\
1, \quad x \leq-h, \\
S(x)=\left\{\begin{aligned}
& \frac{-x-(h-d h)}{d h},-h<x<-(h-d h), \\
& 0 \leq-(h-d h) x \leq 0, \\
& 1, \quad x>0,
\end{aligned}\right.
\end{gathered}
$$

где $n_{0}=1$ - коэффициент преломления воздуха, $n_{c}-$ коэффициент преломления сплошного композита, $S(x)$ определяет удельный вес воздуха и композита в гофрированной части образца. Общий вид зависимости $n(x)$ представлен на рис. 4. Для расчета $n_{c}=\sqrt{\varepsilon}$ воспользуемся формулой для композита с малыми концентрациями цилиндрических включений $[6,25]$ :

$$
\varepsilon=\varepsilon_{h}-\frac{1}{3} n_{w t} \frac{\rho_{h}}{\rho_{c f}} \frac{i \sigma}{2 \pi \nu \varepsilon_{0}},
$$

где $\varepsilon_{h}=3-0.1 i$ - диэлектрическая проницаемость эпоксидной смолы, $n_{w t}-$ массовая концентрация УВ в композите, $\rho_{h}$ и $\rho_{c f}-$ плотность смолы и УВ соответственно, $i$ - мнимая единица, $\sigma=20000 \mathrm{~S} / \mathrm{m}$ - статическая проводимость УВ, $v-$ частота, $\varepsilon_{0}=8.85 \cdot 10^{-12} \mathrm{~F} / \mathrm{m}$ - электрическая постоянная. Так как в композите УВ расположены случайным образом, а поляризуемость вдоль оси тонкого проводящего цилиндра намного больше поперечной поляризуемости, то в (6) возникает коэффициент 1/3 [5,6,25].

Электромагнитный отклик полученных материалов измерялся с помощью скалярного анализатора цепей ELMIKA R2-408R. Образцы композитов вырезались точно под размеры $7.2 \times 3.4 \times 4.5 \mathrm{~mm}$ и помещались в волновод для измерений модулей $S$-параметров $\left(S_{21}\right.$,

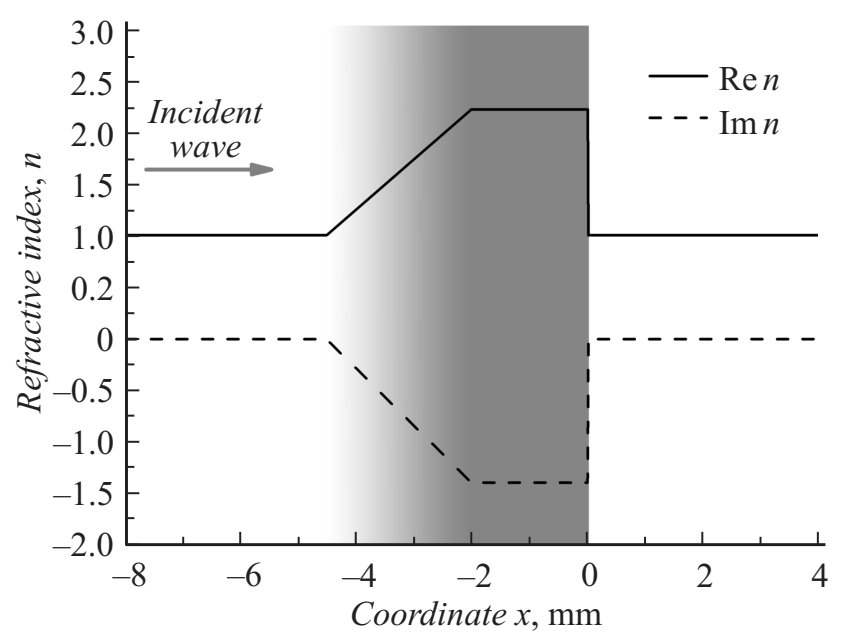

Рис. 4. Пространственная зависимость коэффициента преломления в гофрированном композите на частоте $30 \mathrm{GHz}$ 

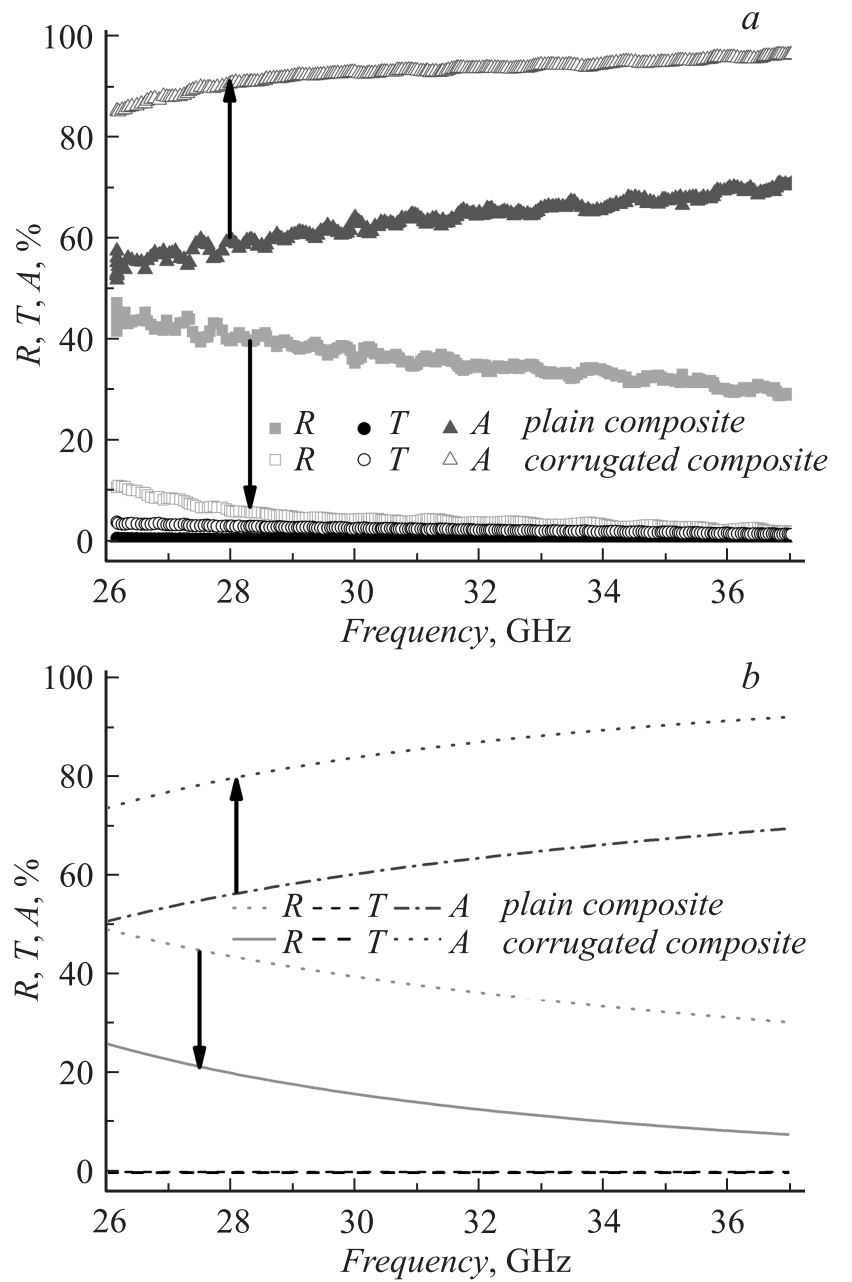

Рис. 5. Частотные зависимости коэффициентов отражения $R$, пропускания $T$ и поглощения $A$ плоскопараллельных и гофрированных композитов толщиной $4.50 \mathrm{~mm}$, содержащих $0.2 \%$ (по массе) УФ: $a-$ эксперимент, $b-$ моделирование.

$S_{11}$ - отношения амплитуд прошедшей и отраженной волн к амплитуде падающей волны соответственно). Гофрированные композиты вырезались так, чтобы направление фрезерования было параллельно большей стороне волновода. Образцы помещались в волновод гофрированной стороной к падающему излучению. На рис. 5, $a$ представлен электромагнитный отклик плоскопараллельных и гофрированных композитов одинаковой толщиной $4.50 \mathrm{~mm}$, содержащих $0.2 \%$ (по массе) УФ. В случае когда излучение падало на плоскую поверхность фрезерованного композита, электромагнитный отклик был практически таким же, как у плоскопараллельного образца.

Из рис. 5, $a$ хорошо видно, что гофрирование поверхности позволяет существенно увеличить коэффициент поглощения композита (с 63 до $92 \%$ на частоте $30 \mathrm{GHz}$ ) при той же общей толщине $4.50 \mathrm{~mm}$. Зависимости на рис. 5, $a$ могут быть удовлетворительно описаны с помощью длинноволнового приближения. Рассмотрим гофрированный композит как плоскопараллельный слой с пространственной зависимостью коэффициента преломления (5), а затем разделим его на $N$ одинаковых частей. При большом $N$ можно $n$ считать внутри каждой части постоянным. В этом случае характеристическая матрица (4) гофрированного композита равна произведению N матриц слоев, входящих в его состав. Результаты расчетов (рис. $5, b$ ) хорошо согласуются с экспериментом. Отметим, что добиться лучшего совпадения с экспериментом можно, если уменьшить проводимость $\sigma$ в (6). Это может объясняться тем, что при фрезеровании часть волокон повреждается и в композите появляется распределение волокон по длине. Короткие волокна вносят меньший вклад в электромагнитный отклик композита вследствие влияния деполяризации. Похожая ситуация часто наблюдается в наноуглеродных композитах $[6,26]$.

Зависимость коэффициента поглощения гофрированных композитов с коэффициентом преломления (5) от компонент $\varepsilon$ сплошного композита на частоте $30 \mathrm{GHz}$ представлена на рис. 6. Из-за менышего отражения значения коэффициента поглощения гофрированных композитов превышают на 10-25\% поглощение в плоскопараллельных образцах аналогичной толщины. Также ослабление интерференции между падающей и отраженной волнами приводит к сглаживанию осцилляций и существенному уширению пика поглощения на рис. 5 по сравнению с рис. 2. Расчеты показывают, что максимально возможные значения поглощения в гофрированных композитах толщиной $4.50 \mathrm{~mm}$ на частоте $30 \mathrm{GHz}$ могут достигать 94\%, в то время как максимум поглощения в плоскопараллельном образце не может превышать 84\%.

Приведенный анализ поглощения в волноводе в целом справедлив и для свободного пространства (для расчетов необходимо просто убрать член $\lambda^{2} / 4$ под корнем в выражении для волнового числа (1)). В свободном пространстве зависимости коэффициента поглощения гофрированных композитов в целом аналогичны рис. 6 . Отметим, что для случая поглощения в свободном

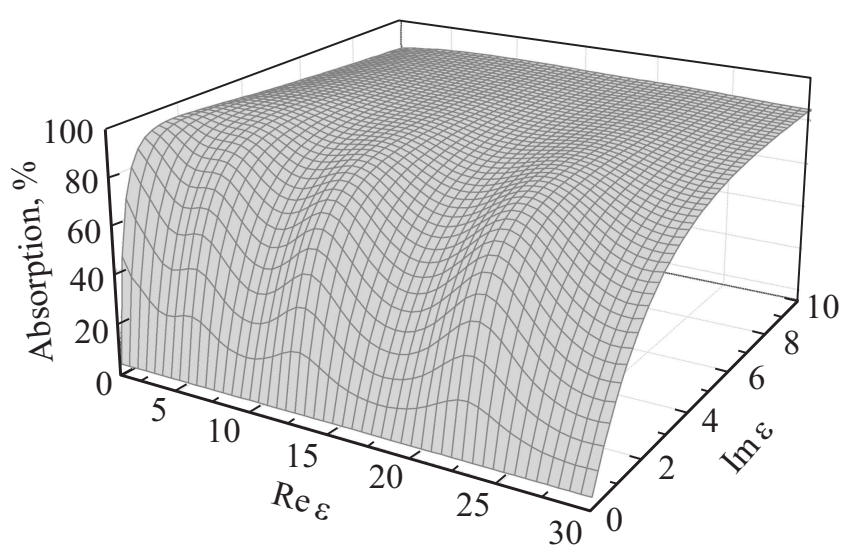

Рис. 6. Зависимость коэффициента поглощения гофрированного композита толщиной $4.50 \mathrm{~mm}$ от компонент $\varepsilon$ на частоте $30 \mathrm{GHz}$. 
пространстве полученные результаты масштабируются и справедливы для других диапазонов частот. Например, при уменьшении частоты в 2 раза и при пропорциональном увеличении размеров образца в 2 раза зависимость поглощения от $\varepsilon$ практически не изменяется. Это накладывает существенные ограничения на минимальную толщину композита, при которой могут быть получены заданные значения коэффициента поглощения в низких частотах. Оценки показывают, что за счет омических потерь удается добиться существенного поглощения при толщине образца, большей, чем половина длины волны падающего излучения.

В заключение еще раз отметим, что использование гофрированных композитов позволяет увеличить коэффициент поглощения, а также снизить массу композита (на 28\% в рассматриваемом композите), что, например, особенно важно в авиастроении. В свою очередь теоретический анализ показывает ограничения, которые накладываются на композиты на основе классических материалов (углеродная сажа, стеклоуглерод, УВ и т.д.). В этой связи весьма перспективными являются исследования свойств композитов на основе углеродных нанотрубок, графена, пиролитического углерода и других наноуглеродных материалов, в которых может наблюдаться недрудевская проводимость и соответственно отклонение от классических законов дисперсии.

Работа выполнена при финансовой поддержке проекта федеральной целевой программы „Исследования и разработки по приоритетным направлениям развития научно-технологического комплекса России на 2014-2020 г.“, уникальный идентификатор ПНИЭР RFMEFI57715X0186.

\section{Список литературы}

[1] Qin F., Brosseau C. // J. Appl. Phys. 2012. Vol. 111. N 6. P. 061 301-24

[2] Kuzhir P., Paddubskaya A., Bychanok D. et al. // Thin Solid Films. 2011. Vol. 519, P. 4114-4118.

[3] Sarto M.S., D'Aloia A.G., Tamburrano A. et al. // IEEE Electromagn. C. 2012. Vol. 54. N 1. Pl. 17-27.

[4] Bychanok D., Plyushch A., Piasotski K. et al. // Phys. Scripta. 2015. Vol. 90. N 9. P. 094019.

[5] Быченок Д., Каныгин М., Окотруб А. идр. // Письма в ЖЭТФ. 2011. Т. 93. №. 10. С. 669-673.

[6] Bychanok D.S., Shuba M.V., Kuzhir P.P. et al.// J. Appl. Phys. 2013. Vol. 114. N 11. P. $114304-7$.

[7] Bychanok D., Kuzhir P., Maksimenko S. et al. // J. Appl. Phys. 2013. Vol. 113. N 12. P. 124 103-6.

[8] Bychanok D., Li S., Sanchez-Sanchez A. et al. // Appl. Phys. Lett. 2016. Vol. 108. P. 013 701-5.

[9] 9 Cao M., Song W., Hou Z. etal. // Carbon. 2010. Vol. 48. N 3. P. $788-796$.

[10] Сонгсонг Ц., Банный В., Самофалов А. идр. // Проблемы физики, математики и техники. 2014. № 21. С. 40-45.

[11] Ipatov M., Zhukova V., Panina L. et al. // PIERS Proc. 2009. Vol. 5. P. $1657-1661$.
[12] Buchner R., Barthel J., Stauber J. // Chem. Phys. Lett. 1999. Vol. 306. P. 57-63.

[13] Withayachumnankul W., Abbott D. // IEEE. Phot. 7. 2009. Vol. 1. P. 99-118.

[14] Stavenga D.G., Foletti S., Palasantzas G. etal. // Proc. Roy. Soc. Lond. Biol.2006. Vol. 273. N 1587. P. 661-667.

[15] Sun C.H., Jiang P., Jiang B. // Appl. Phys. Lett.2008. Vol. 92. N 6. P. 061 112. (2008)

[16] Клочко Н., Хрипунов Г., Мягченко Ю. идр. // ФТП. 2014. т. 48. Вып. 4. С. 549-555.

[17] Born M., Wolf E. // Principles of optics $4^{\text {th }}$ ed. Pergamon Press. 1970.

[18] Angus Mac Leod H. // Thin-Film Optical Filters. $3^{\text {rd }}$ ed. CRC Press, 2001

[19] Batrakov K., Kuzhir P., Maksimenko S. et al. // Sci. Rep. 2014. Vol. 4. P. 7191.

[20] Поглотитель электромагнитных волн „ТОРА“ http:// niipfp.bsu.by/index.php/oborud/tora.

[21] Chung D.D.L. // Carbon. 2011. Vol. 39. N 2. P. 279-285.

[22] Углеродный флок http://nano.bsu.by/products/carbon-flock.

[23] Углеродная нить „Урал“ (Угленить) http://www.sohim.by/ rus/production/carbon/yarn/.

[24] Фрезерный станок с ЧПУ http://cnc.aircraft.by/.

[25] Lakhtakia A., Slepyan G., Maksimenko S. etal. // Carbon. 1998. Vol. 36. N 12. P. 1833-1839.

[26] Shuba M.V., Melnikov A.V., Paddubskaya A.G. etal. // Phys. Rev. B. 2013. Vol. 88. N 4. P. 045 436. (2013). 